\title{
Redox balance: A probable target in the management of immune dysfunction
}

\section{Babatunde Joseph Oso ${ }^{1}$, Olufunke Temiloluwa $0 \mathrm{so}^{2}$ and Adenike Temidayo Oladiji ${ }^{3}$}

${ }^{1}$ Department of Biochemistry. Kings University. Odeomu. Nigeria. Email: basjoe08@gmail.com.

${ }^{2}$ Department of Obstetrics and Gynaecology. Ekiti State University Teaching Hospital. Ado Ekiti. Nigeria.

${ }^{3}$ Department of Biochemistry. University of Ilorin. Nigeria.

\begin{abstract}
Activation of cell-mediated immune is usually interconnected with the generation of oxidative species. The objective of this review was to concisely discuss the interplay between redox balance and immune functions. A qualitative review of peer reviewed papers published in journals and other publications was conducted. The review showed that cellular oxidants which act as signalling molecules could drive biological responses such as those that modulate the productions of proand anti-inflammatory cytokines and immune function. Moreover, beneficial effects of these cellular oxidants could be maintained by an array of defence pathways which include antioxidants, proteins and antioxidant enzymes. When there is an imbalance between increased oxidative species and suppressed antioxidant defences, oxidative stress and associated secondary complications may occur. Therefore, maintaining the redox homeostasis and immune responses through modulation of redox-sensitive inflammatory pathways may offer anticipative possibilities for management of diseases associated with dysfunctional redox homeostasis and immune disorders.
\end{abstract}

Keywords: Oxidants; Antioxidant; Phytochemicals; Immune response.
Received

August 11, 2018

Accepted

August 27, 2018

Released

August 31, 2018

Full Text Article

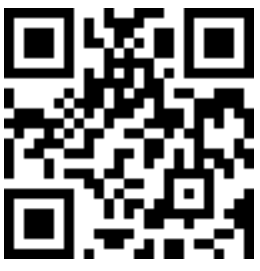

\section{Introduction}

Cellular damage arising from reactive oxygen species (ROS) has been related with the aetiology and pathophysiology of immune dysfunctions and degenerative diseases (Fischer and Maier, 2015). Equally, oxidative stress has been linked to the genesis of many immuno-pathological disorders such as autoimmune and immunodeficiency diseases. Oxidative stress results from 
the cytopathologic corollary of imbalance between the generation of free radicals (formed during cellular respiration by activated phagocytic cells) and the capability of the cell to guard against them.

When oxidative stress occurs, cells put effort to offset the oxidant effects and reinstate the redox balance through activation and/or silencing of genes encoding transcription factors of/and defensive enzymes (Bhattacharyya et al., 2012).

Oxidative stress can be beneficial and harmful; the probable outcome depends on the concentration of the ROSs in the cell. At moderate (low) concentrations, the favourable effects of ROS include defence against infection, control of signal transduction and initiation of mitogenic responses; the beneficial role is achieved when the oxidants' level does not exceed the redox capacities in a cell. However, when the production of oxidants exceeds the capacity of the cell to neutralise the oxidants partly due to overproduction or increase in the generation of the free radicals on one hand and a deficiency of enzymatic and non-enzymatic antioxidants to quench the excessiveness on the other hand, the harmful and damaging effect of the oxidants comes to play: causing biological damages to cellular lipids, proteins, or DNA, disrupting their normal function (Therond, 2006).

Free radicals exert oxidative injurious effects by modifying virtually molecules found in living cells thus the impairment of their respective biological functions (Lobo et al., 2010). Thus, the 'fragile' balance between favourable and damaging effects of oxidants (or free radicals) is a very essential aspect of living cell. Many botanicals have been reported to prevent or cure dysfunctional inflammatory responses (Oso et al., 2017). As a result, there is an intensifying curiosity in identifying plants and characterising the phytochemicals with antioxidant and immunomodulatory activities ever since their possible use in the prevention, management and treatment of ailments has been since ancient times.

Thus, this article reviews the balance of oxidant and antioxidant status as a possible target in the management of disorders that are associated with dysfunctional immune response.

\section{Diseases associated with immune dysfunction}

Generation of ROS is usually increased in the stimulated phagocytes and neutrophils resulting in the generation of considerable local or systemic increase of ROS levels by the immune system. Many studies had, however, related the beneficial and detrimental roles of oxidants in the mediation of immune response and subsequent development of unsuitable immune responses.

\section{Autoimmune disease}

Characteristically, the immune system is able to differentiate the 'aliens' from the organism's 'selfs'. Autoimmunity, however, illustrates a diseased state in which an organism fails to recognise its own cells and tissues, thereby enabling the immune system to mount an attack against its own tissues. Presently, more than 80 clinically distinct human diseases that result, at least in part, from an autoimmune response have been recognised which include multiple sclerosis, rheumatoid arthritis, pernicious anaemia, lupus, type 1 diabetes, vasculitis, Goodpasture's syndrome and Lyme disease (ADCC, 2005). Hypersensitivity to oxidative stress in response to excessive generations of ROS has been assumed to contribute to the inflammatory process at large (Cho and Moon, 2010). Persistent production of ROS has been shown to potentially influence $\mathrm{T}$ cell function which has been associated with 
rheumatoid arthritis (Belikov et al., 2015).

\section{Myalgic Encephalomyelitis/ Chronic Fatigue Syndrome (ME/CFS)}

ME/CFS has been shown to be linked with a chronically activated innate immune system characterised by significant elevated concentrations of oxidative stress markers such as malondialdehyde and protein carbonyls comparable to healthy group (Morris and Maes, 2014). A mechanism was proposed by the authors to explicate the interplay between neuroinflammation (characterised by brain disorders) and oxidative/nitrosative stress in patients with ME/CFS: elevated levels of ROS and $\mathrm{TN}-\alpha$ increase the permeability of endothelial tight junctions in the blood brain barrier and the gut. (Lochhead et al., 2010; Yu et al., 2012) According to the review, these species facilitates neuroinflammation by causing disruption of the blood brain barrier and allowing encephalitogenic $\mathrm{T}$ cells to enter into the CNS (Zajac et al., 1995) and allowing translocation of bacteria and lipopolysaccharides, through the gut increased permeability, into the blood stream. The entry of lipopolysaccharide into the circulation incites the activation of a range of immune-inflammatory responses (Maes et al., 2009).

\section{Immunodeficiency diseases}

Humans infected with HIV have been revealed to be under chronic immune stimulation characterised by elevated generation of ROS and loss of redox maintenance (Awodele et al., 2012). The hyper activation of the immune system has however been suggested to underlying immune deficiency, the basis of acquired immunodeficiency disease syndrome (AIDS) (Hazenberg et al., 2000). Moreover, stress associated with ROS overload has been detected in many tissues of HIV infected individuals using different biochemical markers and diverse bio-techniques (Gil et al., 2003).

\section{Maintenance of oxidants/ antioxidant status and modulation of immune response by an array of defence pathways}

Inflammation and cell-mediated immune activation are associated with the generation of ROS. (Jiang et al., 2012). Cellular oxidants which can act as signalling molecules can drive biological responses such as those that modulate the productions of pro- and antiinflammatory cytokines (Hussain et al., 2016). Beneficial effects of the cellular oxidants are balanced by an array of defence pathways comprising the endogenous and dietary antioxidants (Hussain et al., 2016). When there is an imbalance between increased oxidative species and suppressed antioxidant defences, oxidative stress and associated secondary complications may occur. Therefore, to balance the oxidative stress to treat/manage/prevent immune associated disorders, targeting the redoxsensitive inflammatory pathways and transcription factors may possibly offer optimistic assurance for the management of oxidative stress and immune disorders. Such targeting includes increasing various endogenous and exogenous antioxidants enzymes while maintaining the free radicals at low concentration. Several plants have been reported to enhance healing from diverse ailments and their curative and diseasepreventing potential, at least in part, has been associated to their influence on cellular antioxidant and immune function. (Spelman et al., 2006; Oso et al., 2017). The bioactive constituents of dietary phytochemicals are believed to modulate the inflammatory processes, proliferation, cell signalling pathways, apoptosis and redox balance. Majority of these natural products and botanicals have been examined and established to 
mediate inflammatory response (Hatcher et al., 2008). For instance, polyphenols have been shown to exert their antiinflammatory properties at various levels through the modulation of bio-signalling pathways of nuclear factor kappa-lightchain-enhancer of activated B cells and mitogen-activated protein kinase by modulating activity of cyclooxygenase, productions of cytokines and ROS (Ichikawa et al., 2004; deVries et al., 2008). Several phytocompounds are also endowed with the ability to activate the nuclear factor E2-related factor 2/antioxidant response element (Nrf2/ARE) pathway initiating the expressions of scavengers of oxidative species and protective enzymes thus enhancing the maintenance of cellular redox homeostasis (Johnson et al., 2008).

\section{Conclusion}

Cellular generation of oxidants can stimulate the onset of inflammatory response and dysfunctional immune system which can invariably progress to patho-physiological damage. Management of oxido-immuno-induced pathologies may be enhanced by targeting and influencing several of the redox-sensitive inflammatory signalling pathways. This approach may offer anticipative possibilities for treatment of diseases interrelated with redox imbalance and immune disorders.

\section{Conflicts of interest}

The authors declare that they have no conflict of interest in the publication.

\section{References}

ADDC - Autoimmune Disease Coordinating Committee. Progress in Autoimmune Disease Research, 2005. Available from: <http://www.niaid.nih.gov/topics/autoimm une/Documents/adccfinal.pdf>. Accessed on: Apr. 20, 2018.
Awodele, 0.; Olayemi, S. O.; Nwite, J. A.; Adeyemo, T. A. Investigation of the levels of oxidative stress parameters in HIV and HIVTB co-infected patients. Jounal of Infection in the Developing Countries, v. 6 , no. 1 , p. 79-85, 2012. Available from: <http://www.jidc.org/index.php/journal/art icle/view/22240433>. Accessed on: Apr. 28, 2018.

Belikov, A.; Schraven, B.; Simeoni, L. T cells and reactive oxygen species. Jounal of Biomedical Science, 22:85, 2015. https://doi.org/10.1186/s12929-015-0194-3

Bhattacharyya, A.; Chattopadhyay, R.; Mitra, S.; Crowe, S. Oxidative stress: An essential factor in the pathogenesis of gastrointestinal mucosal diseases. Physiological Review, v. 94, no. 2, p. 329-354, 2012. https://doi.org/10.1152/physrev.00040.2012

Cho, Y. S.; Moon, H. The role of oxidative stress in the pathogenesis of asthma. Allergy asthma. Allergy, Asthma \& Immunology Research, v. 2, no 3, p. 183-187, 2010. https://doi.org/10.4168/aair.2010.2.3.183

deVries, H. E.; Witte, M.; Hondius, D.; Rozemuller, A. J.; Drukarch, B.; Hoozemans, J.; van Horssen, J. Nrf2-induced antioxidant protection: a promising target to counteract ROS-mediated damage in neurodegenerative disease? Free Radical Biology and Medicine, v. 45, no. 10, p. 1375-1383, 2008. https://doi.org/10.1016/j.freeradbiomed.20 08.09.001

Fischer, R.; Maier, O. Interrelation of oxidative stress and inflammation in neurodegenerative disease: Role of TNF. Oxidative Medicine and Cellular Longevity, v. 2015, ArticleID, 610813, 2015. https://doi.org/10.1155/2015/610813

Gil, L.; Martinez, G.; Gonzalez, I.; Alvarez, A.; Molina, R.;Tarinas, A.; Leon, O. S.; Perez J. Contribution to characterization of oxidative stress in HIV/AIDS patients. Pharmacological Research, v. 47, p. 217 224, 2003. https://doi.org/10.1016/S10436618(02)00320-1

Hatcher, H.; Planalp, R.; Cho, J.; Torti, F. M.; Torti, S. V. Curcumin: From ancient medicine to current clinical trials. Cellular and Molecular Life Sciences, v. 65 , no. 11 , p.1631-1652, $2008 . \quad$ https://doi.org/ 10.1007/s00018-008-7452-4 
Hazenberg, M. D.; Stuart, J. W.; Otto, S. A.; Borleffs, J. C.; Boucher, C. A.; de Boer, R. J.; Miedema, F.; Hamann, D. T-cell division in human immunodeficiency virus (HIV)-1 infection is mainly due to immune activation: A longitudinal analysis in patients before and during highly active antiretroviral therapy (HAART). Blood, v. 95, no. 1, p. 249-255, 2000. Available from: <http://www.bloodjournal.org/cgi/pmidloo kup?view=long\&pmid=10607709>. Accessed on: Apr. 20, 2018.

Hussain, T.; Tan, B.; Yin, Y.; Blanchier, F.;Tossou, M. C. B.; Rahu, N. Oxidative stress and inflammation: What polyphenols can do for us? Oxidative Medicine and Cellular Longevity,v. 2016, AritcleID 7432797, 2016. https://doi.org/10.1155/2016/7432797

Ichikawa, D.; Matsui, A.; Imai, M.;Sonoda, Y.;Kasahara, T. Effect of various catechins on the IL-12p40 production by murine peritoneal macrophages and a macrophage cell line, J774.1. Biological and Pharmaceutical Bulletin, v. 27, no. 9, p. 1353-1358, 2004. https://doi.org/ 10.1248/bpb.27.1353

Jiang, X.; Bar, H. Y.; Yan, J.; West, A. A.; Perry, C. A.; Malysheva, O. V.; Devapatla, S.; Pressman, E.; Vermeylen, F. M.; Wells, M. T.; Caudill, M. A. Pregnancy induces transcriptional activation of the peripheral innate immune system and increases oxidative DNA damage among healthy third trimester pregenant women. PloS One, v. 7, no. 11, e46736, 2012. https://doi.org/ 10.137/journal.pone.0046736

Johnson, J. A.; Johnson, D. A.; Kraft, A. D.; Calkins, M. J.; Jakel, R. J.; Vargas, M. R.; Chen P. C. The Nrf2-ARE pathway: An indicator and modulator of oxidative stress in neurodegeneration. Annals of New York Academy of Sciences, v. 1147, p.61-69, 2008. https://doi.org/10.1196/annals. 1427.036

Lobo, V., Phatak, A., Chandra, N. Free radical, antioxidants and functional foods: Impact on human health. Pharmacognosy Review, v. 4, no. 8, p. 118-126, 2010. https://doi.org/ 10.4103/0973-7847.70902

Lochhead, J. J.; McCaffrey, G.; Quigley, C. E.; Finch, J.; DeMarco, K. M.;Nametz, N.; Davis, T. P. Oxidative stress increases blood-brain barrier permeability and induces alterations in occluding during hypoxia-reoxygenation. Journal of Cerebral Blood Flow \&
Metabolism, v. 30, no. 9, p. 1625-1636, 2010. https://doi.org/10.1038/jcbfm.2010.29

Maes, M.; Yirmyia, R.; Noraberg, J.; Brene, S.; Hibbeln, J.; Perini, G.; Kubera, M.; Bob, P.; Lerer, B.; Maj, M. The inflammatory and neurodegenerative (I\&ND) hypothesis of depression: leads for future research and new drug developments in depression. Metabolic Brain Disease, v. 24, no. 1, p. 2753, 2009. https://doi.org/10.1007/s11011008-9118-1

Morris, G.; Maes, M. Oxidative and Nitrosative Stress and Immune-Inflammatory Pathways in Patients with Myalgic Encephalomyelitis (ME)/Chronic Fatigue Syndrome (CFS). Current Neuropharmacology, v. 12, no. 2, p. 168-185, 2014. https://doi.org/10.2174/ 1570159X11666131120224653

Oso, B. J.; Oyewo, E. B.; Oladiji, A. T. Ethanolic, n-hexane and aqueous partitioned extracts of Xylopia aethiopica fruit modulated inflammatory responses in turpentine oil induced acute inflammation in male Wistar rats. International Journal of Research Health Sciences, v. 5, no. 2, p. 1-10, 2017. Available from: <http://ijrhs.org/view issue.php?title=Ethanolic-n-hexane-andaqueous-partitioned-extracts-of-Xylopiaaethiopica-fruit-modulated-inflammatoryresponses-in-turpentine-oil-induced-acuteinflammation-in-male-Wistar-rats $>$. Accessed on: Apr. 20, 2018.

Spelman, K.; Burns, J. J.; Nichols, D.; Winters, N.; Ottersberg, S.; Tenborg, M. Modulation of cytokine expression by traditional medicines: A review of herbal immunomodulators. Alternative Medicine Review, v. 11, no. 2, p.128-150, 2006. Available from: <http://archive.foundationalmedicinereview. com/publications/11/2/128.pdf>. Accessed on: Apr. 20, 2018.

Therond, P. Oxidative stress and damages to biomolecules (lipids, proteins, DNA). Annales Pharmaceutiques Francaises, v. 64 , no. 6, p. 383-389, 2006. Available from: <http://www.masson.fr/masson/MDOI-APF11-2006-64-6-0003-4509-101019200606807>. Accessed on: Apr. 20, 2018.

Yu, L. C.; Wang, J. T.; Wei, S. C.; Ni, Y. H. Hostmicrobial interactions and regulation of intestinal epithelial barrier function: From physiology to pathology. World Journal of Gastrointestinal Pathophysiology, v. 3, no. 1 , p. 27-43, 2012. https://doi.org/ 10.4291/wjgp.v3.i1.27 
Zajac, A. J.; Muller, D.; Pedersen, K.;Frelinger, J. A.; Quinn, D. G. Natural killer cell activity in lymphocytic choriomeningitis virus infected beta 2-microglobulin-deficient mice. International Immunology, v. 7, p. 15451556, 1995. https://doi.org/10.1093/ intimm/7.10.1545

CC License information: This is an open-access article distributed under the terms of the Creative Commons Attribution License, which permits unrestricted use, distribution, and reproduction in any medium, provided the original work is properly cited. 